\title{
Response of the total ozone to energetic electron precipitation events
}

\author{
Arseniy Karagodin ${ }^{a}$, Irina Mironova ${ }^{a *}$, Anton Artamonov ${ }^{b c}$ and Natalia \\ Konstantinova $^{d}$ \\ ${ }^{a}$ St. Petersburg State University, Institute of Physics, St. Petersburg, Russia \\ ${ }^{b}$ Research Institute for Space Medicine Federal Research Clinical Center of Federal Biomedical Agency \\ of Russia, Moscow, Russia \\ Space Climate Research Unit, University of Oulu, Finland \\ ${ }^{d}$ State Scientific Center of the Russian Federation Institute of Biomedical Problem of the RAS, Moscow, \\ Russia
}

\begin{abstract}
In this paper we investigate response of the total ozone column to energetic electron precipitation (EEP) observed by bremsstrahlung effect. The list of EEP events was prepared by members of the balloon experiments of the Lebedev Physical Institute. Here we used superposed epoch analysis and the days with EEP events are registered during winter (November - February) and summer (June - August) months from 1970 to 2012 were chosen as key dates. This period corresponds approximately to three solar cycles. Data of the total ozone column were collected by single coherent total ozone dataset, called the Multi Sensor Reanalysis (MSR). A long series of data of the total ozone column is allowed us to study the response of ozone content to 90 winter and 103 summer EEP events. The obtained ozone sensitivity to the events of energetic electron precipitation is clearly pronounced during local winters in the high latitudes Northern and Southern Hemispheres (60-80 NH and 60-80 SH). In the high latitudes of the Northern Hemisphere, during winter months, the total ozone content can be reduced by up to $10 \mathrm{DU}$ after energetic electron precipitation with minimum observed on the first day after EEP events. Response of the total ozone, over high latitudes Northern Hemisphere, to EEP events can be opposite during summer months.
\end{abstract}

Keywords: energetic electron precipitation (EEP) events, total ozone column, high latitudes atmosphere

*Corresponding author: Irina Mironova (i.a.mironova@ spbu.ru and irini.mironova@gmail.com) Preprint submitted to Journal of Atmospheric and Solar-Terrestrial Physics 


\section{Introduction}

Electrons and protons of different energy range can hit and penetrate to the Earth atmosphere. Such type of particles are said to be precipitation particles. The atmospheric processes connected with the impact of different energies of solar protons are well reproduced in a huge amount of papers, for example Jackman et al. (2008); Rozanov et al. (2012); Mironova et al. (2012b); Mironova and Usoskin (2013, 2014); Krivolutsky et al. (2017). The impact of energetic electron precipitation on the atmosphere and climate is still an outstanding question. The main issues of debates are: changes of frequency and intensity of the electron precipitation events, as well as a question about the range of electron energies that can be the most important for atmospheric chemical changes. Some recent papers (Rozanov et al., 2016; Arsenovic et al., 2016; Turunen et al., 2016; Lam and Tinsley, 2016; Zhou et al., 2016; Seppälä et al., 2015; Mironova et al., 2015; Andersson et al., 2014; Mironova et al., 2012a) demonstrate an interest of science community to this problem.

In this paper we concentrate on the precipitating electrons that are registered by balloon experiments and their effect on the total ozone variability over polar latitudes.

\section{Experimental data}

\subsection{Energetic electron precipitation events}

The information about energetic electron precipitation (EEP) was taken from the catalogue of EEP events prepared basing on the balloon experiments (Makhmutov et al., 2016). The balloon measurements have been performed by the Lebedev Physical Institute since 1961 till now. The dataset of 524 EEP events was collected in Murmansk region about $68 \mathrm{~N}$ (Makhmutov et al., 2016). The regular balloon measurements of charge particle fluxes in the atmosphere are carried out from the ground level up to 30$35 \mathrm{~km}$ above the sea level. Usually, precipitating electrons are absorbed in the upper atmosphere but generated bremsstrahlung (X-rays) can be significant in the middle and the lower polar/high latitudinal stratosphere (Artamonov et al., 2016, 2017). That allows one to register EEP by balloon measurements (Makhmutov et al., 2016). In the catalogue (Makhmutov et al., 2016), each EEP event is characterized by characteristic energy of electron spectra $\mathrm{E}_{0}-$ in $\mathrm{keV}$ and $\mathrm{J}(\mathrm{E}>20 \mathrm{keV})$ integral flux in $\mathrm{cm}^{-2} \mathrm{~s}^{-1}$. Energy spectra of registered electrons are based on an assumption that primary flux of precipitating electrons at the top of atmosphere can be expressed by an exponential spectrum, $\mathrm{J}_{e}(\mathrm{E})=A_{e} \cdot \exp \left(-\mathrm{E} / \mathrm{E}_{0}\right), A_{e}$ parameter of the flux of incident electrons, given in $\mathrm{cm}^{-2} \mathrm{~s}^{-1}$ $\mathrm{keV}^{-1}$.

For our study we selected 90 winter (November - February) EEP events and 103 summer (June - August) EEP events that had been occurred from 1970 to 2012. The selection of years was motivated by the data set of observation of the total ozone column. 
Figure 1 and Figure 2 show winter and summer EEP events separated by characteristic energy of electron spectra $\mathrm{E}_{0}$. During winter time from November to February (19702012) there were registered 22 EEP events with characteristic energy of spectra $E_{0}<$ $10 \mathrm{keV}, 47 \mathrm{EEP}$ events with spectra $10 \mathrm{keV}<\mathrm{E}_{0}<100 \mathrm{keV}$ and other two groups are characterized by spectra $100 \mathrm{keV}<\mathrm{E}_{0}<1 \mathrm{MeV}$ (12 EEP events) and $\mathrm{E}_{0}>1 \mathrm{MeV}$ (9 EEP events). During summer time from June to August (1970-2012) there were registered 32 EEP events with characteristic energy of spectra $\mathrm{E}_{0}<10 \mathrm{keV}, 56 \mathrm{EEP}$ events with spectra $10 \mathrm{keV}<\mathrm{E}_{0}<100 \mathrm{keV}$ and other two groups are characterized by spectra $100 \mathrm{keV}<$ $\mathrm{E}_{0}<1 \mathrm{MeV}$ (10 EEP events) and $\mathrm{E}_{0}>1 \mathrm{MeV}$ (5 EEP events). Here one can see that according to the catalogue of events, energetic electron precipitation with characteristic energy of electron spectra less than $100 \mathrm{keV}$ will be more often registered by the balloon measurements. And as an example, Figure 3 presents ionization profiles for these four grouped events.
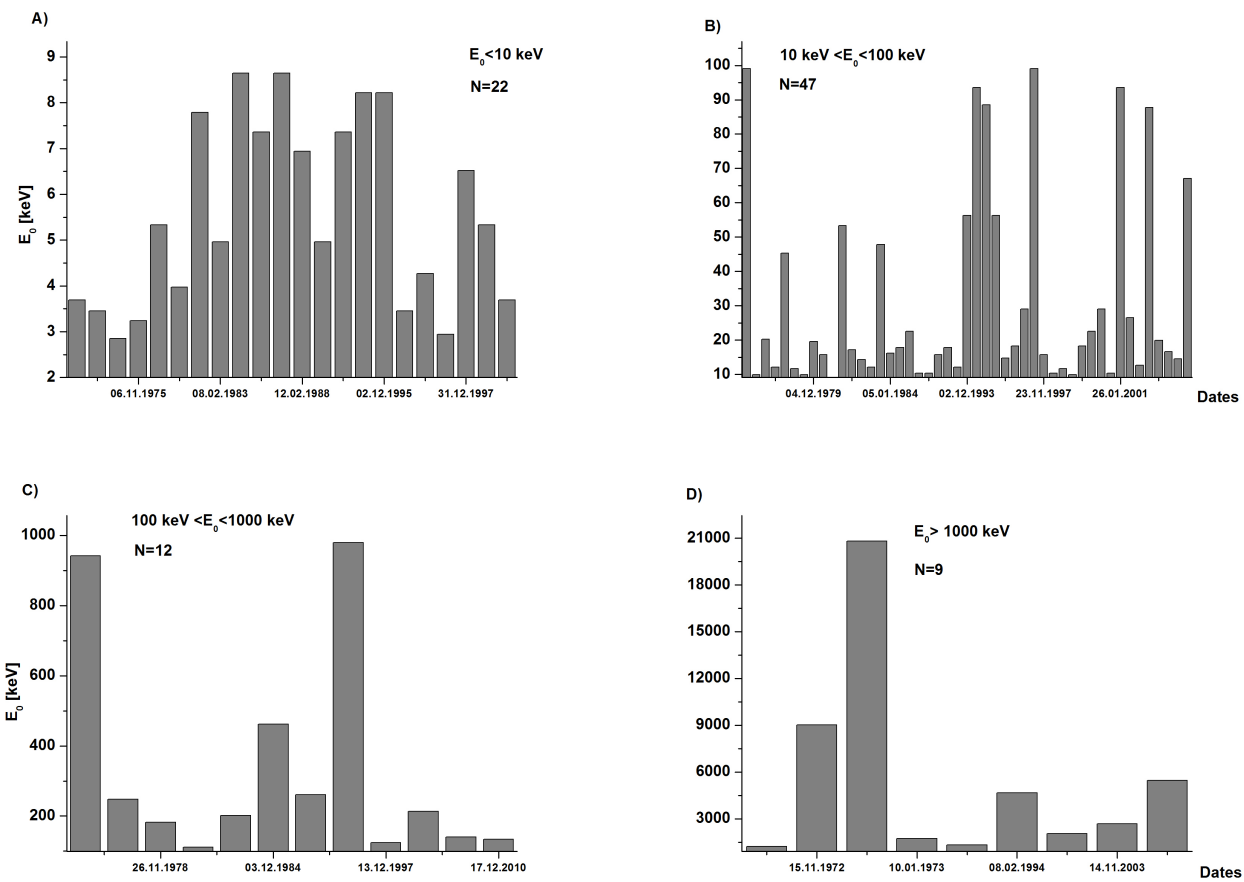

Figure 1: Energetic electron precipitation events from November to February during 1970 - 2012 years. The events are divided by characteristic energy of electron spectra $\mathrm{E}_{0} . \mathrm{N}$ - number of events in each case. Number of all winter EEP events equal 90.

Table 1 corresponds Figure 3. Ionization rates during electron precipitation were calculated basing on the scheme presented by papers Artamonov et al. $(2017,2016)$. Figure 3 demonstrates variability of ion production rates during EEP events (Makhmutov 

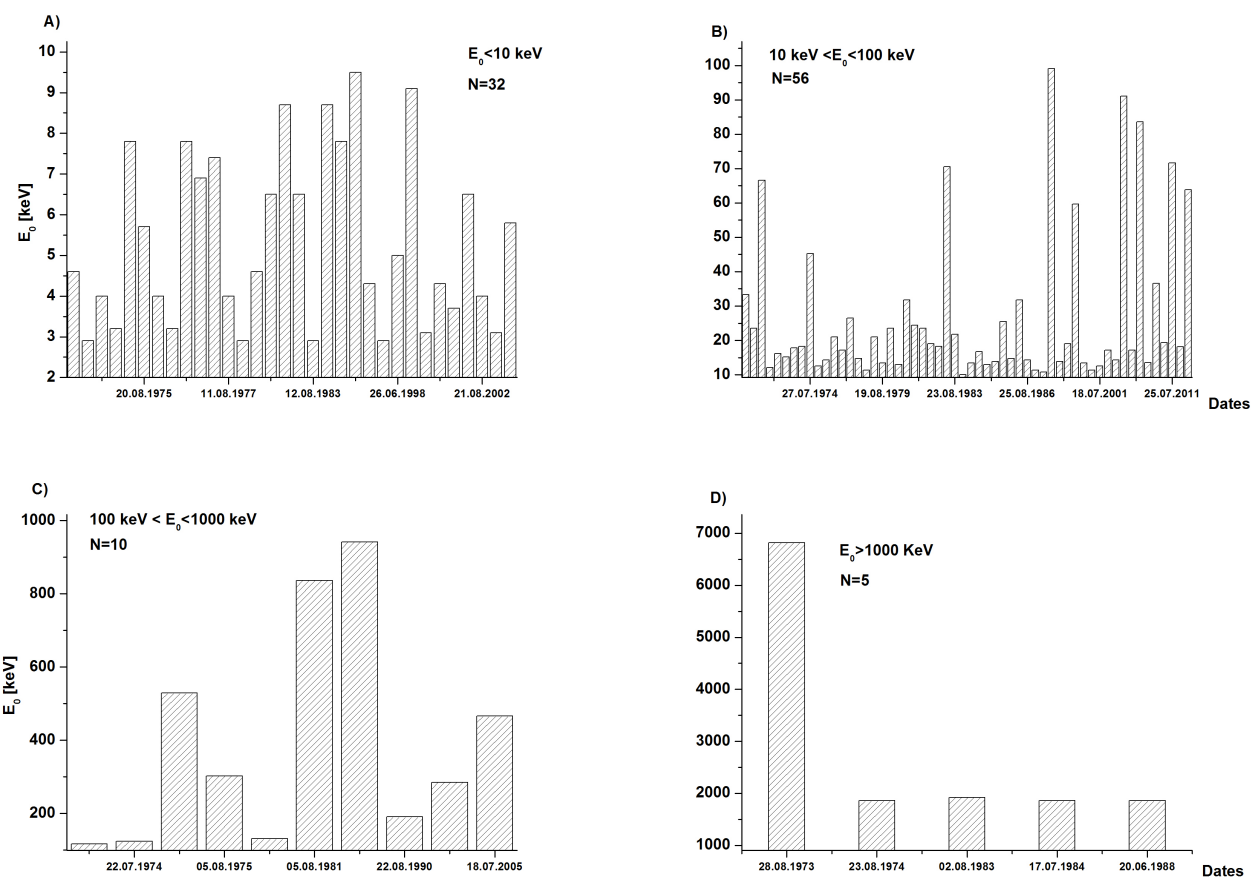

Figure 2: Energetic electron precipitation events from June to August during 1970 - 2012 years. The events are divided by characteristic energy of electron spectra. $\mathrm{N}$ - number of events in each case. Number of all summer EEP events equal 103.

et al., 2016). Four ionization profiles coincide with four cases of EEP events, see Table 1. In Figure 3 the first maximum of ionization rates induced by electron precipitation is strongly dependent on the flux of incident electrons and the characteristic energy of electron spectra. EEP events with characteristic energy of electron spectra less than 100 $\mathrm{keV}$ produce the ionization mostly in the upper atmosphere about $90 \mathrm{~km}$. From the other side EEP events with characteristic energy of electron spectra more than $100 \mathrm{keV}$ generate ionization mostly in the middle atmosphere about $60 \mathrm{~km}$. One can see, Table 1, that less characteristic energy of electron spectra is the stronger the flux of incident electrons should be registered by balloon measurements. Second maimum of ionization rates, see Figure 3, confirms that energetic electron precipitation can be detected via radiation that generated by X-ray bremsstrahlung in the stratosphere. Since Figure 1 and Figure 2 show that, in most cases, electron precipitation events are characterized by the energy of electron spectra less than $100 \mathrm{keV}$. Therefore we can conclude, the main ionization induced by the EEP is noticeable in the region of polar termosphere and mesosphere. From the other side all energies of precipitating electrons contribute to the ionization of the stratosphere. 
Table 1: Selected events that correspond to four cases of different spectra of EEP and presented by Figure 1 and Figure 2. First case - events with spectra $E_{0}<10 \mathrm{keV}$. Second case - events with spectra $10 \mathrm{keV}<\mathrm{E}_{0}$ $<100 \mathrm{keV}$. Third case - events with spectra $100 \mathrm{keV}<\mathrm{E}_{0}<1000 \mathrm{keV}$. Fourth case - events with spectra $\mathrm{E}_{0}$ $>1000 \mathrm{keV}$. Time of events is associated to observations during balloon experiments.

\begin{tabular}{lcccc}
\hline Number of cases & 1 & 2 & 3 & 4 \\
\hline Day. Month. Year & 3.11 .1988 & 27.12 .1975 & 3.12 .1984 & 2.11 .1995 \\
UT hours : min, Start event & $6: 49$ & $8: 15$ & $9: 03$ & $7: 07$ \\
UT hours : min, Finish event & $7: 03$ & $8: 30$ & $9: 18$ & $7: 46$ \\
$\mathrm{~A}_{e}, \mathrm{~cm}^{-2} \mathrm{~s}^{-1} \mathrm{keV}^{-1}$ & $2.09 \mathrm{E} 7$ & $3.43 \mathrm{E} 4$ & $1.4 \mathrm{E}-1$ & $6.44 \mathrm{E}-3$ \\
$\mathrm{E}_{0}, \mathrm{keV}$ & 4.96 & 20.3 & 462 & 2050 \\
\hline
\end{tabular}

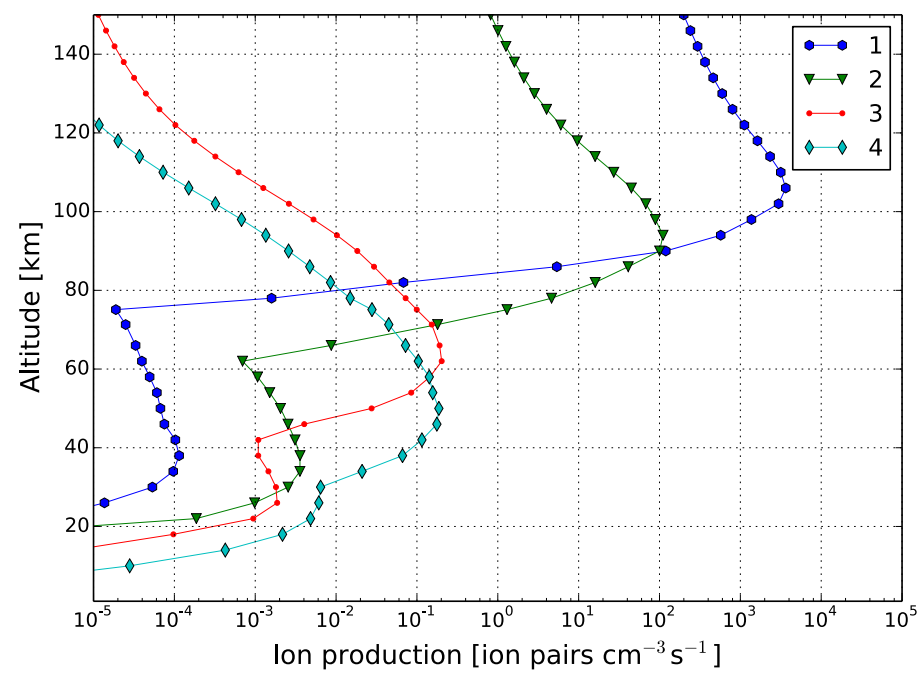

Figure 3: The ionization profiles of energetic electron precipitation. Current number of profile coincides current number of the case in Table 1. First ionization profile corresponds to EEP events with spectra $\mathrm{E}_{0}$ $<10 \mathrm{keV}$. Second ionization profile - EEP events with spectra $10 \mathrm{keV}<\mathrm{E}_{0}<100 \mathrm{keV}$. Third ionization profile corresponds to EEP events with spectra $100 \mathrm{keV}<\mathrm{E}_{0}<1000 \mathrm{keV}$. Fourth ionization profile - EEP events with spectra $\mathrm{E}_{0}>1000 \mathrm{keV}$.

\subsection{Total ozone}

The Multi Sensor Reanalysis (MSR) data of total ozone are distributed by the Tropospheric Emission Monitoring Internet Service (TEMIS), http://www.temis.nl. This database was enclosed by the measurements of ozone in a column of the atmosphere since 1970 up to 2012. The total ozone is measured in Dobson Unit (DU), that indicates how much ozone there is in the air above a certain point on the Earth. A proper unit would thus be a kilogram per square meter. The MSR dataset has been created from all available ozone column data measured by polar orbiting satellites. The MSR 
(van der A et al., 2015, 2010) data include total ozone satellite retrieval datasets from the instruments TOMS (on the satellites Nimbus-7 and Earth Probe), SBUV (Nimbus-7, NOAA-9, NOAA-11 and NOAA-16), GOME (ERS-2), SCIAMACHY (Envisat), OMI (EOS-Aura), and GOME-2 (Metop-A). For each satellite the product of an overpass dataset closest to the ground station has been created. The overpass MSR data has 175 overpass stations over the whole world. The total ozone data by MSR has been obtained four times per day: at $6,12,18$ and $24 \mathrm{UT}$, respectively.

\section{Superposed epoch analysis}

We took reanalysis data of the total ozone column on the reason that real measurements are poorly represented for polar winter. Comparison of the obtained results (by MSR data) with real measurements of the total ozone column is presented by Figure 4 . Figure 4 describes the results of superposed epoch analysis of the total ozone over stations located near Murmansk region. Key dates of superposed epoch analysis are the days with energetic electron precipitation (EEP) events (Makhmutov et al., 2016).

The real satellite data were obtained by Total Ozone Mapping Spectrometer (TOMS) over Northern Hemisphere since 1978 till 2005 years. Data were achieved by NASAs Earth Science Data Systems, https://earthdata.nasa.gov. This data suit records from a few satellite missions such as TOMS Nimbus-7 (1978-1991), TOMS Meteor-3 (1991-1994) and TOMS Earth Probe (1996-2005).

Figure 4 shows the response of total ozone content obtained by MSR and TOMS data. The upper panel of Figure 4 presents the MSR overpass stations Andoya island (Norway) 69 N 15 E, Sodankylä (Finland) 67 N 26 E and Kiruna (Sweden) 67 N 20 E. The number of winter EEP events (1978 - 2005) is 90. The low panel of Fig. 4 presents the TOMS overpass stations such as Sodankylä (Finland) 67 N 26 E, Murmansk (Russia) 68 N 33 E, Kiruna (Sweden) 67 N 20 E and Arkhangelsk (Russia) 64 N 40 W. Due to different data gaps the amount of EEP events for each TOMS overpass station were noticeably plummeted. Fig. 4 also demonstrates the reduction of the winter total ozone by up to $10 \mathrm{DU}$ after the observation of electron precipitation with minimum observed on the first day after the registered event. It is also important to notice that the variability of total ozone column obtained by MSR and TOMS data shows the same response to EEP events.

\subsection{Response of the high latitudinal total ozone over the Northern and Southern Hemi- spheres to the local winter EEP events}

Here, we selected more stations in the polar auroral ovals of both hemispheres. Figure 5 presents selected stations over the Northern and the Southern polar Hemispheres. On the left side of Fig. 5 we show selected stations of the Northern Hemisphere (NH). Here there are 15 overpass stations (marked by red points) and Murmansk (marked by yellow star) as a station of balloon measurements of EEP events. On the right side of 
Fig. 5 we show selected stations of the Southern Hemisphere (SH). At this part 21 polar overpass stations are marked by red points.

Figure 6 demonstrates total ozone variability, over high latitudes of the Northern and Southern Hemispheres, during local winters as response to the local winter EEP events. For the preparation of Figure 6 we excluded from the MSR ozone data a seasonal trend which is the approximation data by cubic spline interpolation for period 1971-2012. Two years 1970, 1979 did not included in this investigation because a lot of gaps in the data. At the next step of the investigation, for every event and every station a difference of the total ozone between 6 days after and 6 days before EEP events (Roldugin et al., 2000) was calculated. The left panel of Fig. 6 presents total ozone variability over polar region of the Northern Hemisphere (15 stations, see left picture of Fig. 5) before and after winter EEP (90 events during November - February, see Fig. 1). One can see that during local winter time over the most stations of the Northern Hemisphere the total ozone content is reduced after precipitating relativistic electrons. The same effect obtained in the total ozone content of the Southern Hemisphere. The right panel of Fig. 6 presents total ozone variability over polar region of the Southern Hemisphere (21 stations, see right picture of Fig. 5) before and after local winter EEP (103 summer events (Makhmutov et al., 2016) during May - June, see Fig. 2). During local winter time, over the most stations of the Southern Hemisphere, the total ozone content is also decreases after energetic electron precipitation events.

\subsection{Response of the high latitudinal total ozone over the Northern Hemisphere to sum- mer and winter EEP events}

Figure 7 presents response of the total ozone column over the Northern Hemisphere to the local summer and the local winter EEP events. Figure 7 was built like as Fig.4 of the paper by Roldugin et al. (2000). Fig. 7 represents the latitudinal variability of the total ozone difference before and after EEP events during local winter and local summer time. Seasonal trend of total ozone variability was excluded for years 1971-2012. The total ozone variability was calculated, as in previous case, as total ozone difference between 6 days after and 6 days before EEP events. We need to notice that response of the NH total ozone before and after local winter EEP events was already presented by the left panel of Fig. 6. At Figure 7 one can see that in most cases total ozone content after EEP events decreases during local winter and increases during local summer. Obtained effect is well represented over high latitude band 70-80 $\mathrm{NH}$.

Both figures, Fig. 7 and Fig. 6, show variability of the total ozone during 6 days before and after EEP events. In all cases changes in the total ozone content can lead by up to 7 DU. Surely a response is different when comparing stations, seasons and hemispheres. Anyway these figures, as well as Figure 4 confirm that during winter time energetic electron precipitation will lead to destruction of the ozone content. 


\section{Summary and Conclusion}

This paper introduces results of the investigation on the total ozone response to the energetic electron precipitation (EEP) events were detected by the high latitudinal balloon observations during approximately three cycles of solar activity, 1970-2012 years. As output on response of the total ozone content to EEP events we summarize the main obtained results:

- In the high latitudes of the Northern Hemisphere, during winter months, the total ozone content can be reduced by up to $10 \mathrm{DU}$ after energetic electron precipitation. The minimum of ozone reduction can be observed on the first day after EEP events.

- During local winter time most energetic electron precipitation can lead to destruction of the total ozone content over high latitudes of the Northern and Southern Hemispheres.

- The obtained ozone sensitivity to summer and winter EEP events is clear pronounced in the high latitude band 70-80 NH.

- Over the high latitudes of the Northern Hemisphere response of the total ozone to EEP events can be opposite during summer months.

It is well known that enhancements of $\mathrm{NO}_{x}$ due to energetic particle precipitation can change the ozone balance of the stratosphere. This so-called indirect effect is widely discussed in various papers (Randall et al., 2007; Baumgaertner et al., 2009; Rozanov et al., 2012; Arsenovic et al., 2016). This mechanism suggests that long-lived $\mathrm{NO}_{x}$ source by particle precipitation and its transport from the mesosphere to the stratosphere in the polar vortex are important for stratospheric ozone. The effect on stratospheric ozone is possible due to coupling atmospheric dynamics and propagating downwards by changing polar winds and atmospheric wave propagation, particularly during the polar winter. Nevertheless to see any changes of stratospheric polar ozone are taking time of the order of weeks.

This mechanism seems does not work for the explanation of our observations. We need to stress that our obtained results show response of the total ozone balance to EEP events on the daily scale.

Statistical analysis of the EEP events indicates that in most cases, electron precipitation events are characterized by the energy of electron spectra less than $100 \mathrm{keV}$. Calculation of induced ionization by energetic electron precipitation allowed us to make following conclusions: 1) an additional ionization induced by EEP events with energies of electron spectra less than $100 \mathrm{keV}$ can be noticeable in the region of polar termosphere and mesosphere; 2) all characteristic energies of electron spectra during EEP contribute to ionization of the polar mesosphere and stratosphere. 
From one side, basing on the obtained results, we can give an assumption that during winter time energetic electron precipitation can destroy mesospheric ozone via shortterm $\mathrm{HO}_{x}$ formation (Andersson et al., 2014; Seppälä et al., 2015). Andersson et al. (2014) show that EEP events strongly affect ozone at $60-80 \mathrm{~km}$ leading to extremely large (up to $90 \%$ ) short-term ozone depletion. This effect may be perceptible in the polar total ozone content during winter time.

From another side, since the main ozone is concentrated into the stratosphere we can speculate that EEP can directly destroy polar stratospheric ozone during winter time too. Now it is hard to speculate on the any mechanisms related to this hypothesis. More work is needed to prove this idea.

\section{Acknowledgements}

IM acknowledges for support of St.Petersburg State University through the Grant 11.42.675.2017. AA thanks Yliopiston Apteekin rahasto Fund for their help and support of the work on this paper. Authors thank "Google Earth" team for the possibility to use their map tools.

\section{References}

Andersson, M. E., Verronen, P. T., Rodger, C. J., Clilverd, M. A., Seppälä, A., 2014. Missing driver in the Sun-Earth connection from energetic electron precipitation impacts mesospheric ozone. Nature Communications 5, 5197.

Arsenovic, P., Rozanov, E., Stenke, A., Funke, B., Wissing, J., Mursula, K., Tummon, F., Peter, T., 2016. The influence of middle range energy electrons on atmospheric chemistry and regional climate. J. Atmos. Solar-Terr. Phys. 149, $180-190$.

Artamonov, A., Mironova, I., Kovaltsov, G., Mishev, A., Plotnikov, E., Konstantinova, N., 2017. Calculation of atmospheric ionization induced by electrons with non - vertical precipitation: updated model CRAC- EPII. Adv. Space. Res. 59, 2295-2300.

Artamonov, A. A., Mishev, A. L., Usoskin, I. G., 2016. Model CRAC:EPII for atmospheric ionization due to precipitating electrons: Yield function and applications. J. Geophys. Res. 121, 1736-1743.

Baumgaertner, A. J. G., Jöckel, P., Brühl, C., 2009. Energetic particle precipitation in ECHAM5/MESSy1 Part 1: Downward transport of upper atmospheric $\mathrm{NO}_{x}$ produced by low energy electrons. Atmos. Chem. Phys. 9, 2729-2740.

Jackman, C. H., Marsh, D. R., Vitt, F. M., Garcia, R. R., Fleming, E. L., Labow, G. J., Randall, C. E., LópezPuertas, M., Funke, B., von Clarmann, T., Stiller, G. P., 2008. Short- and medium-term atmospheric constituent effects of very large solar proton events. Atmos. Chem. Phys. 8 (3), 765-785.

Krivolutsky, A. A., Vyushkova, T. Y., Mironova, I. A., Mar. 2017. Changes in the chemical composition of the atmosphere in the polar regions of the Earth after solar proton flares ( $3 \mathrm{~d}$ modeling). Geomagnetism and Aeronomy 57, 156-176.

Lam, M. M., Tinsley, B. A., 2016. Solar wind-atmospheric electricity-cloud microphysics connections to weather and climate. J. Atmos. Solar-Terr. Phys. 149, 277-290.

Makhmutov, V., Bazilevskaya, G., Stozhkov, Y., Svirzhevskaya, A., Svirzhevsky, N., 2016. Catalogue of electron precipitation events as observed in the long-duration cosmic ray balloon experiment. J. Atmos. Solar-Terr. Phys. 149, 258 - 276.

Mironova, I., Tinsley, B., Zhou, L., 2012a. The links between atmospheric vorticity, radiation belt electrons, and the solar wind. Adv. Space. Res. 50, 783-790. 
Mironova, I. A., Aplin, K. L., Arnold, F., Bazilevskaya, G. A., Harrison, R. G., Krivolutsky, A. A., Nicoll, K. A., Rozanov, E. V., Turunen, E., Usoskin, I. G., 2015. Energetic Particle Influence on the Earth's Atmosphere. Space Sci. Rev. 194, 1-96.

Mironova, I. A., Usoskin, I. G., 2013. Possible effect of extreme solar energetic particle events of September-October 1989 on polar stratospheric aerosols: a case study. Atmos. Chem. Phys. 13, 85438550 .

Mironova, I. A., Usoskin, I. G., 2014. Possible effect of strong solar energetic particle events on polar stratospheric aerosol: a summary of observational results. Env. Res. Letters 9 (1), 015002.

Mironova, I. A., Usoskin, I. G., Kovaltsov, G. A., Petelina, S. V., 2012b. Possible effect of extreme solar energetic particle event of 20 January 2005 on polar stratospheric aerosols: direct observational evidence. Atmos. Chem. Phys. 12, 769-778.

Randall, C. E., Harvey, V. L., Singleton, C. S., Bailey, S. M., Bernath, P. F., Codrescu, M., Nakajima, H., Russell, J. M., 2007. Energetic particle precipitation effects on the Southern Hemisphere stratosphere in 1992-2005. J. Geophys. Res. 112, D08308.

Roldugin, V. C., Beloglazov, M. I., Remenets, G. F., 2000. Total ozone decrease in the Arctic after REP events. Annal. Geophys. 18, 332-336.

Rozanov, E., Calisto, M., Egorova, T., Peter, T., Schmutz, W., Jul. 2012. Influence of the Precipitating Energetic Particles on Atmospheric Chemistry and Climate. Surv. Geophys. 33, 483-501.

Rozanov, E., Georgieva, K., Mironova, I., Tinsley, B., Aylward, A., 2016. Foreword: Special issue on effects of the solar wind and interplanetary disturbances on the earth's atmosphere and climate. J. Atmos. SolarTerr. Phys. 149, $146-150$.

Seppälä, A., Clilverd, M. A., Beharrell, M. J., Rodger, C. J., Verronen, P. T., Andersson, M. E., Newnham, D. A., 2015. Substorm-induced energetic electron precipitation: Impact on atmospheric chemistry. Geophys. Res. Lett. 42, 8172-8176.

Turunen, E., Kero, A., Verronen, P. T., Miyoshi, Y., Oyama, S.-I., Saito, S., 2016. Mesospheric ozone destruction by high-energy electron precipitation associated with pulsating aurora. J. Geophys. Res. 121 (19), 11,852-11,861, 2016JD025015.

van der A, R. J., Allaart, M. A. F., Eskes, H. J., 2010. Multi sensor reanalysis of total ozone. Atmos. Chem. Phys. 10, 11277-11294.

van der A, R. J., Allaart, M. A. F., Eskes, H. J., 2015. Extended and refined multi sensor reanalysis of total ozone for the period 1970-2012. Atmos. Meas. Techniq. 8, 3021-3035.

Zhou, L., Tinsley, B., Chu, H., Xiao, Z., 2016. Correlations of global sea surface temperatures with the solar wind speed. J. Atmos. Solar-Terr. Phys. 149, 232-239. 